\title{
Diuretics as pathogenetic treatment for heart failure
}

This article was published in the following Dove Press journal:

International Journal of General Medicine

21 January 20II

Number of times this article has been viewed

\section{Maya Guglin}

University of South Florida,

Tampa, FL, USA
Correspondence: Maya Guglin Heart Failure Program, Department of Cardiovascular Services, University of South Florida, Tampa, FL 336|3, USA Tel +l 2483463507

Email mguglin@gmail.com
Abstract: Increased intracardiac filling pressure or congestion causes symptoms and leads to hospital admissions in patients with heart failure, regardless of their systolic function. A history of hospital admission, in turn, predicts further hospitalizations and morbidity, and a higher number of hospitalizations determine higher mortality. Congestion is therefore the driving force of the natural history of heart failure. Congestion is the syndrome shared by heart failure with preserved and reduced systolic function. These two conditions have almost identical morbidity, mortality, and survival because the outcomes are driven by congestion. A small difference in favor of heart failure with preserved systolic function comes from decreased ejection fraction and left ventricular remodeling which is only present in heart failure with decreased systolic function. The magnitude of this difference reflects the contribution of decreased systolic function and ventricular remodeling to the progression of heart failure. The only treatment available for congestion is fluid removal via diuretics, ultrafiltration, or dialysis. It is the only treatment that works equally well for heart failure with reduced and preserved systolic function because it affects congestion, the main pathogenetic feature of the disease. Diuretics are pathogenetic therapy for heart failure.

Keywords: heart failure, diuretics, congestion, systolic function, diastolic function, ejection fraction

To the memory of Kenneth Lee Baughman

\section{Introduction}

In the classic paradigm of heart failure, the downward spiral of disease progression starts with decreased cardiac output, resulting in kidney hypoperfusion with the activation of the renin-angiotensin-aldosterone axis, retention of sodium and water, stimulation of the sympathetic nervous system, vasoconstriction, and further hypoperfusion. This concept works well if an initial offense such as acute myocardial infarction, myocarditis, or idiopathic cardiomyopathy jeopardizes myocardial contractility. However, these cases do not represent the whole spectrum of heart failure. In fact, they represent only about half of all heart failure.

About one third to one half of heart failure patients have normal systolic function on the basis of left ventricular ejection fraction. Patients with heart failure with preserved systolic function do not have decreased cardiac output, and so do not fit into the classic paradigm of heart failure. One hypothesis explaining the origin of heart failure in these subsets of patients is based on the concept of decreased "effective blood flow". ${ }^{1}$ However, several studies by Maurer et al provided the evidence that blood flow is normal or increased in a substantial number of patients with heart failure with preserved systolic function. ${ }^{2,3}$ 
Multiple studies have compared the natural course, morbidity, and mortality in heart failure with preserved and reduced systolic function. Patients with preserved ejection fraction are usually older, more frequently women, have less coronary disease and myocardial infarction, and have more atrial fibrillation and other comorbidities. They have higher systolic blood pressures and pulse pressures ${ }^{4}$ as well as a higher prevalence of left ventricular hypertrophy, aortic valve disease, and anemia. ${ }^{5}$

Despite multiple dissimilarities in patient populations, the reported mortality is either similar ${ }^{5-11}$ or somewhat better in those with preserved systolic function. ${ }^{12,13}$ In fact, the survival curves are identical in some studies, indicating that it is basically the same condition with the same natural course.

Symptoms in heart failure with preserved and reduced systolic function are similar, physical examination is also similar, and peak oxygen consumption $\left(\mathrm{VO}_{2}\right)$ and the slope of the ventilation/carbon dioxide production ratio on the cardiopulmonary stress test is indistinguishable. ${ }^{14}$ Even the financial burden is similar, in that patients with heart failure and normal ejection fraction consume as many health care resources as those with reduced ejection fraction. ${ }^{15}$

These observations can be explained only if we accept that the two groups of patients share a common syndrome which determines the course and prognosis to a much greater extent than all the dissimilarities, including systolic function. All the evidence indicates that this syndrome is congestion.

\section{Congestion causes heart failure symptoms regardless of ejection fraction}

According to the Acute Decompensated Heart Failure National Registry (ADHERE), most patients admitted for heart failure are "wet" or congested, with dyspnea, rales, edema, radiological signs of fluid overload, or a combination of these features. ${ }^{16}$ Current technologies providing continuous hemodynamic monitoring support these clinical observations with hard data from the measured parameters.

During heart failure exacerbations, right ventricular pressures increase by about $25 \%$, starting several days prior to clinical deterioration. Heart failure management guided by this information resulted in reduction of hospitalizations, which dropped from 1.08 per patient-year to 0.47 per patient-year $(57 \%$ reduction, $P<0.01) .{ }^{17}$ Similar hemodynamic changes were reported from the Chronicle Offers Management to Patients with Advanced Signs and Symptoms of Heart Failure trial (COMPASS-HF), in which
New York Heart Association (NYHA) III or IV patients were monitored by a Chronicle ${ }^{\circledR}$ implantable cardioverter device. In patients with normal and decreased systolic function, which differed according to multiple structural and hemodynamic parameters, the mechanism of exacerbation was exactly the same, ie, intracardiac pressures increased significantly before clinically evident volume overload episodes, and the percentage of pressure change from baseline was similar. ${ }^{18}$ Furthermore, successful treatment of acute decompensated heart failure, regardless of systolic function, was associated with a decrease in diastolic pressures..$^{19}$ In summary, congestion is a syndrome shared by heart failure with normal and reduced systolic function. Congestion not only causes symptoms, but it also worsens the prognosis.

\section{Congestion causes pulmonary hypertension and cardiorenal syndrome}

Two syndromes, ie, pulmonary hypertension and cardiorenal syndrome, are consistently associated with a poor prognosis in heart failure. Increased pulmonary pressure is linked to increased short-term and long-term mortality in heart failure. A 5-mmHg increase in right ventricular systolic pressure results in a $9 \%$ increase in mortality in heart failure with both normal and reduced ejection fraction. ${ }^{20}$ Increased right ventricular systolic pressure is a stronger predictor of death than left ventricular ejection fraction. ${ }^{21}$

Several studies have indicated that the severity of diastolic rather than systolic cardiac dysfunction determines the degree of elevation of pulmonary arterial pressure. In individuals with normal ejection fraction and unknown heart failure status, mean pulmonary artery pressure was shown to be $31.1 \pm 6 \mathrm{mmHg}$ in normal diastolic function, $35.6 \pm 10.2 \mathrm{mmHg}$ in Grade 1 diastolic dysfunction (impaired relaxation), $38.9 \pm 10.6 \mathrm{mmHg}$ in Grade 2 (pseudonormal), and $55.1 \pm 11.4 \mathrm{mmHg}(P<0.001)$ in Grade 3 (restrictive pattern). ${ }^{22}$ In untreated patients with dilated cardiomyopathy, the $\mathrm{E}$ wave deceleration rate and the degree of mitral regurgitation were the strongest independent predictors of pulmonary hypertension, while ejection fraction was only a minor contributor. The reversal of pulmonary hypertension after treatment with an angiotensin-converting enzyme inhibitor and diuretics occurred only in patients whose diastolic left ventricular function improved from restrictive or pseudonormal to impaired relaxation pattern. ${ }^{23}$

In left ventricular systolic dysfunction, pulmonary artery systolic pressure was elevated on echocardiography in most patients, ranging from 23 to $87 \mathrm{mmHg}$, and correlated with 
parameters of diastolic dysfunction. Ejection fraction was not an independent predictor of pulmonary artery pressure. ${ }^{24}$

Cardiorenal syndrome also worsens the prognosis in heart failure. In ADHERE, $60 \%$ of patients had moderate or severe renal insufficiency. Mortality rates, length of hospitalization, need for mechanical ventilation, intensive care, and cardiopulmonary resuscitation all increase with the degree of baseline renal dysfunction. ${ }^{25}$

Mortality associated with renal dysfunction was higher in those with heart failure with normal rather than reduced systolic function. ${ }^{26}$ The presence of at least moderate tricuspid regurgitation was associated with a lower glomerular filtration rate in heart failure, indicating that elevated renal venous pressure plays a role in cardiorenal syndrome. ${ }^{27}$ In the Cleveland Clinic cohort, heart failure patients with worsening renal function had higher central venous pressure, both upon admission and after intensive medical therapy. Furthermore, the ability of central venous pressure to predict renal dysfunction was consistent across the spectrum of systemic blood pressure, pulmonary capillary wedge pressure, cardiac index, and estimated glomerular filtration rates. ${ }^{28}$

In summary, two conditions, ie, pulmonary hypertension and renal dysfunction, worsen the clinical course and prognosis in heart failure, and develop as a result of elevated filling pressures, or congestion.

\section{Congestion worsens the course and prognosis in heart failure}

Hospitalizations for heart failure occur due to volume overload or congestion. It was recently demonstrated that the risk of further hospitalizations and death increases progressively and independently with each episode of heart failure exacerbation, and the total number of heart failure hospitalizations is a strong predictor of mortality. ${ }^{29,30}$ When pulmonary hypertension secondary to volume overload is present in chronic hemodialysis patients, it predicts high mortality. ${ }^{31}$ Any sign of congestion adds to mortality. Mortality rates almost double from no signs to three or more signs of congestion ( $11 \%$ versus $20 \%$, respectively; $P<0.0001){ }^{32}$

The relationship between congestion and systolic function may be more complex than is currently thought. Myocardium easily accumulates interstitial fluid, and the resulting myocardial edema compromises contractility. ${ }^{33}$ Extrapolating these findings, one can conclude that congestion, regardless of its origin, can result in decreased systolic function.

Congestion can facilitate electric instability of the heart. Elevated brain natriuretic peptide produced by a stretched cardiac muscle has been associated with sudden cardiac death in hypervolemic patients. ${ }^{34}$ Additional confirmation of the profound pathophysiological role of congestion can also be found in echocardiography.

\section{Severity of congestion reflected in diastolic but not systolic dysfunction}

In daily clinical practice, left ventricular systolic function is often estimated using ejection fraction, yet little evidence supports the correlation of ejection fraction with actual hemodynamic parameters. In acute heart failure patients, only a weak correlation was found between cardiac index and ejection fraction $(\mathrm{r}=0.25 ; P=0.0003)$, and no correlation existed between ejection fraction and wedge pressure. ${ }^{35}$ In another study, measurements of left ventricular systolic performance, ie, stroke work, ejection fraction, and contractility by $\mathrm{dP} / \mathrm{dt}$, did not differ significantly between patients with heart failure with normal systolic function and normal controls. The authors concluded that the underlying pathophysiology causing symptoms and signs of heart failure did not reflect abnormalities in left ventricular systolic properties, but more likely abnormalities in diastolic function, which was the predominant and necessary factor for the occurrence of heart failure in these patients. ${ }^{36}$

Unlike ejection fraction, diastolic dysfunction on echocardiography is closely correlated with intracardiac filling pressures. Abnormal echocardiographic diastolic parameters, especially an elevated E/e' ratio (ratio of peak velocity of early diastolic inflow to early diastolic mitral annular velocity), indicate elevated filling pressures. ${ }^{37-44}$ In a large population-based study, patients with heart failure and preserved systolic function in Olmsted County, Minnesota, had markedly different left ventricular end-diastolic pressure and diastolic echo parameters, especially E/e', compared with both normal controls and hypertensive patients, whereas cardiac index was similar in all three cohorts. ${ }^{45}$

A high E/e' ratio reflects elevated intracardiac pressures, regardless of etiology of heart failure and ejection fraction. Elevated filling pressures in healthy hearts produce a restrictive pattern on echocardiography. When intravenous fluids were given to healthy dogs, their echoes demonstrated restrictive left ventricular filling. ${ }^{46}$

Interestingly, in patients with very advanced systolic heart failure, the correlation between E/e' and wedge pressure becomes weaker. In a recent series from Cleveland Clinic, no correlation was found between E/e' ratio and wedge pressure in patients with larger left ventricular volumes, severely reduced cardiac indexes, or biventricular 
pacemakers. ${ }^{47}$ This likely means that congestion becomes less important than low cardiac output in very advanced heart failure.

\section{Diastolic dysfunction predicts poor prognosis regardless of systolic function}

Diastolic dysfunction predicts the prognosis in heart failure patients with both normal and decreased ejection fraction. In systolic heart failure, the primary endpoint of death, transplantation, or heart failure hospitalization was independently predicted by parameters of diastolic function, including shorter deceleration time, a lower ratio of pulmonary vein systolic to diastolic velocity, and increased E/e' levels. . $^{48,49}$ In another study, the mitral E/e' ratio $(P<0.001)$ and the Tei index (index of myocardial performance incorporating both systolic and diastolic time) but not the ejection fraction, were the only independent predictors of death or heart failure admission $(P=0.019) .{ }^{50}$ Within a cohort with severely decreased ejection fraction $\leq 30 \%$, diastolic indexes of mitral inflow significantly predicted poor outcomes, while ejection fraction did not. ${ }^{51} \mathrm{~A}$ restrictive filling pattern was the only independent predictor of death or appropriate defibrillator shock. ${ }^{52}$ In pooled data from 3540 patients with heart failure across the entire spectrum of ejection fraction, a restrictive filling pattern was associated with a twofold increase in the risk of death, and was independent of ejection fraction, class, and age..$^{53}$ Diastolic dysfunction is also strongly and inversely associated with exercise capacity. Patients with a high E/e' have reduced exercise tolerance..$^{54}$

Different studies have demonstrated that elevation of brain natriuretic peptide either correlates better with diastolic dysfunction than with systolic dysfunction, or correlates only with diastolic dysfunction, and does not correlate with ejection fraction at all. ${ }^{55}$

In summary, advanced diastolic dysfunction reflects the severity of congestion, and predicts morbidity and mortality in heart failure patients regardless of ejection fraction.

\section{Heart failure exists without systolic dysfunction, but not without diastolic dysfunction}

Although approximately $30 \%-50 \%$ of patients with heart failure have normal systolic function, hardly any heart failure patients have normal diastolic function. In a series of 206 patients with clinical heart failure, diastolic dysfunction by echocardiography was present in $>90 \%$, regardless of ejection fraction. ${ }^{55}$ In another series of 126 heart failure patients with ejection fraction $<35 \%$, none had normal diastolic function. ${ }^{56}$

In the Olmstead County heart failure cohort, only $10 \%$ of patients with preserved ejection fraction and $5 \%$ of those with reduced ejection fraction had normal diastolic function. ${ }^{6}$ In another study that enrolled randomly selected residents rather than heart failure patients, only one in 45 participants with a validated diagnosis of heart failure had normal diastolic function. In participants with an ejection fraction $<50 \%$, only one fifth $(20.5 \%)$ had normal diastolic function. ${ }^{57}$

According to the Mayo Clinic algorithm for diagnosing diastolic dysfunction, ${ }^{58}$ ejection fraction $<50 \%$ is not compatible with normal diastolic function. If the $\mathrm{E} / \mathrm{A}$ ratio is normal, it immediately places the patient in the "pseudonormal" range and presumes elevated filling pressures.

In summary, while systolic dysfunction may or may not be present in heart failure, diastolic dysfunction is universal. It reflects the presence of congestion which is common to heart failure with any degree of systolic function.

\section{Heart failure with reduced and preserved ejection fraction}

Comparison of heart failure with preserved and reduced systolic function demonstrates that disease progression in these two cohorts is strikingly similar. A slight difference in the natural course and prognosis in favor of preserved systolic function has at least two explanations. The first one has to do with patient selection. In all the relevant published studies, patients were diagnosed as having heart failure with preserved systolic function according to clinical, most commonly the Framingham, criteria. Left ventricular filling pressure was neither measured by catheterization nor estimated by diastolic dysfunction on echocardiography. This could result in overdiagnosis of heart failure. In a study by Caruana et al, ${ }^{59} 102$ of 109 patients with normal ejection fraction diagnosed with heart failure by their internists had other conditions, including obesity, chronic obstructive pulmonary disease, and coronary artery disease, that could explain their symptoms, and only seven had heart failure. It is also possible that some cohorts representing heart failure with preserved systolic function are contaminated by patients having conditions other than heart failure. These patients may be partially responsible for slightly more favorable outcomes.

However, there is another factor determining the difference. Decreased ejection fraction and left ventricular remodeling are present in heart failure with reduced systolic function, but 
are absent in preserved systolic function. Decreased ejection fraction and left ventricular remodeling creates an excess mortality in heart failure with reduced systolic function. It adds electrical instability, leading to a higher rate of sudden cardiac death, in this subset of patients. Sudden cardiac death occurs more frequently in those with decreased ejection fraction than in those with normal ejection fraction ( $21 \%$ versus $16 \%$, respectively) ${ }^{60}$ or even versus $2 \%$ as per the Duke Databank for Cardiovascular Disease. ${ }^{61}$

The ultimate treatment for heart failure with reduced systolic function is a left ventricular assist device or heart transplantation, which is practically never utilized in heart failure with normal systolic function, except for specific cases of restrictive or hypertrophic obstructive cardiomyopathy. It is likely that, at some point in time, left ventricular dilatation and remodeling reaches a critical limit and becomes the driving force of the downward spiral of terminal heart failure. The angiotensin-converting enzyme inhibitors and beta-blockers work in systolic heart failure because they slow down and partially reverse left ventricular remodeling. Without such remodeling, as in heart failure with preserved systolic function, they do not have a substrate to work on. All clinical trials testing drugs used successfully in reduced ejection fraction failed to demonstrate their benefit in the subset with preserved systolic function. The difference in morbidity and mortality between heart failure with preserved and reduced ejection fraction measures the contribution of the low output syndrome, together with electric instability created by left ventricular remodeling, to the natural course of heart failure.

Advances in heart failure treatment from 1991 to 2001 have led to better survival in patients with reduced, but not preserved, systolic function. The one-year survival rate trended toward worsening in the preserved systolic function group, but improved in the group with depressed ejection fraction (from $87.7 \%$ to $81.0 \%$ and from $76 \%$ to $84 \%$, respectively). ${ }^{62}$ This occurred because, while new treatment modalities were implemented for left ventricular remodeling and sudden cardiac death (features unique to heart failure with decreased systolic function), treatment for congestion remained the same, ie, with diuretics.

\section{Diuretics are the universal treatment for heart failure}

If the common denominator of heart failure is decreased output, the mainstay of heart failure treatment should be inotropic agents. However, the role of inotropes in heart failure is limited. They are mostly used at the extreme of the heart failure spectrum, ie, those with severely impaired systolic function.

Because the common feature of heart failure is congestion, the mainstay of heart failure treatment is decongestion, or diuretics. In inpatient or outpatient settings and in systolic or diastolic heart failure, diuretics are invariably the top prescribed drug. In ADHERE, diuretics were used in $64.8 \%$ and $65.5 \%$ on hospital admission, $67 \%$ and $78.8 \%$ during hospitalization, and $79.5 \%$ and $83.7 \%$ on discharge in patients with heart failure with preserved and reduced ejection fraction, respectively. ${ }^{63}$

Several studies have attempted to randomize heart failure patients to diuretics or no diuretics, primarily through diuretic withdrawal in patients with already established treatment for heart failure. Richardson et al, ${ }^{64}$ Cowley et al, ${ }^{65}$ van Kraaij et al, ${ }^{66}$ Mathur et al, ${ }^{67}$ Andrews et al, ${ }^{68}$ and Grinstead et a ${ }^{69}$ have all demonstrated that patients with heart failure deteriorate so quickly after discontinuation of diuretics that they have to be reinstituted on diuretic therapy within weeks.

Richardson et $\mathrm{l}^{64}$ substituted captopril for furosemide in symptomatic heart failure in a double-blind, randomized study. Of 14 patients taken off diuretics, four (28.6\%) developed pulmonary edema or severe dyspnea and required immediate reinstitution of furosemide within eight weeks. In another study, patients who were on diuretics for heart failure could only tolerate withdrawal of this medication for a median duration of six weeks. ${ }^{66}$ Mathur et $\mathrm{al}^{67}$ conducted a randomized, double-blind, crossover, placebo-controlled trial lasting 16 weeks and found that none of the heart failure patients included could stay off diuretics. Grinstead et al ${ }^{69}$ demonstrated that $20(71 \%)$ of 41 stable heart failure patients taken off diuretics and randomized to lisinopril or placebo had to be restarted on diuretics due to worsening congestion within 12 weeks (median 15 days), with no difference between the lisinopril and placebo arms of the study. Finally, a meta-analysis of loop diuretics in heart failure found a statistically significant survival benefit of these drugs, even though many studies included in this analysis did not enroll patients with symptomatic heart failure, as demonstrated in a previous review. ${ }^{70}$

Several studies, most of which were retrospective, demonstrated that use of diuretics or higher doses of diuretics are associated with a poorer prognosis in general and higher mortality in particular, even after adjustments for multiple comorbidities. ${ }^{71-73}$ In none of these studies were patients randomized to receive loop diuretics versus no diuretics or 
placebo. Loop diuretics were prescribed by the physician guided by symptoms, ie, congestion. Simple adjustment for NYHA class cannot correct this selection bias because NYHA classification takes into account primarily signs of left ventricular dysfunction (dyspnea) but does not include edema, ascites, and anasarca, which reflect primarily right ventricular failure. Meanwhile, diuretics are prescribed for both conditions. Therefore, the diuretic dose reflects the severity of heart failure better than all other comorbidities taken together because the empiric dose of loop diuretics is matched to the severity of congestion. In the absence of directly measured intracardiac pressures, the dose of loop diuretics is the best measure of congestion we have. The higher the requirement for diuretics, the higher is the morbidity and mortality. No large prospective, randomized, placebo-controlled trials in heart failure have justified the use of diuretics. Such trials cannot be conducted because patients with heart failure do not survive without diurectics. A recent subanalysis of the Evaluation Study of Congestive Heart Failure and Pulmonary Artery Catheterization Effectiveness study (ESCAPE) demonstrated reduced mortality in patients with systolic heart failure undergoing more aggressive diuresis, even though this was achieved at the cost of worsening renal function. ${ }^{74}$

\section{Conclusion}

Heart failure as a syndrome develops when there is an elevation in left ventricular filling pressure. Clinically it presents as congestion, regardless of etiology and systolic function. Congestion is a common denominator shared by all patients with heart failure. It can be identified invasively by direct measurement of intracardiac pressures, or noninvasively by signs of diastolic dysfunction on echocardiography. The severity of congestion determines symptoms, morbidity, natural course of the disease, and mortality in heart failure, as well as major complications, including pulmonary hypertension and cardiorenal syndrome. The best available treatment for congestion is diuretics which work equally well in heart failure with preserved and reduced systolic function.

Many patients with heart failure develop elevated left ventricular filling pressures and congestion as a result of decreased systolic function. Their natural course is somewhat worse because, in addition to congestion, they have left ventricular remodeling and decreased cardiac output, as well as electrical instability, resulting in ventricular tachycardia, ventricular fibrillation, and sudden cardiac death. Besides diuretics, they can benefit from other treatments either reversing left ventricular remodeling or preventing sudden cardiac death, including angiotensin-converting enzyme inhibitors, beta-blockers, aldosterone antagonists, cardiac resynchronization therapy, defibrillators, left ventricular assist devices, and heart transplantation.

Further advances in heart failure treatment should be expected from better monitoring of intracardiac pressures and more accurate and timely decongestion. This will improve the clinical course of all heart failure patients with normal or decreased ejection fraction. It will also result in less severe complications, eg, cardiorenal syndrome and pulmonary hypertension, which could further improve survival. Clinical trials targeting these syndromes should not focus only on patients with preserved or reduced systolic function but rather on all heart failure population.

\section{Disclosure}

The author reports no conflict of interest in this work.

\section{References}

1. Andrew P. Diastolic heart failure demystified. Chest. 2003;124(2): 744-753.

2. Maurer MS, King DL, El-Khoury Rumbarger L, Packer M, Burkhoff D. Left heart failure with a normal ejection fraction: Identification of different pathophysiologic mechanisms. J Card Fail. 2005;11(3): 177-187.

3. Maurer MS, Burkhoff D, Fried LP, Gottdiener J, King DL, Kitzman DW. Ventricular structure and function in hypertensive participants with heart failure and a normal ejection fraction: The Cardiovascular Health Study. J Am Coll Cardiol. 2007;49(9):972-981.

4. Ansari M, Alexander M, Tutar A, Massie BM. Incident cases of heart failure in a community cohort: Importance and outcomes of patients with preserved systolic function. Am Heart J. 2003;146(1): $115-120$.

5. Berry C, Hogg K, Norrie J, Stevenson K, Brett M, McMurray J. Heart failure with preserved left ventricular systolic function: A hospital cohort study. Heart. 2005;91(7):907-913.

6. Bursi F, Weston SA, Redfield MM, et al. Systolic and diastolic heart failure in the community. JAMA. 2006;296(18):2209-2216.

7. Fonarow GC, Stough WG, Abraham WT, et al. Characteristics, treatments, and outcomes of patients with preserved systolic function hospitalized for heart failure: A report from the OPTIMIZE-HF Registry. J Am Coll Cardiol. 2007;50(8):768-777.

8. Varela-Roman A, Gonzalez-Juanatey JR, Basante P, et al. Clinical characteristics and prognosis of hospitalised inpatients with heart failure and preserved or reduced left ventricular ejection fraction. Heart. 2002;88(3):249-254.

9. Bhatia RS, Tu JV, Lee DS, et al. Outcome of heart failure with preserved ejection fraction in a population-based study. $N$ Engl J Med. 2006; 355(3):260-269.

10. Varela-Roman A, Grigorian L, Barge E, Bassante P, de la Pena MG, Gonzalez-Juanatey JR. Heart failure in patients with preserved and deteriorated left ventricular ejection fraction. Heart. 2005;91(4):489-494.

11. Senni M, Redfield MM. Heart failure with preserved systolic function. A different natural history? J Am Coll Cardiol. 2001;38(5):1277-1282.

12. Vasan RS, Larson MG, Benjamin EJ, Evans JC, Reiss CK, Levy D. Congestive heart failure in subjects with normal versus reduced left ventricular ejection fraction: Prevalence and mortality in a populationbased cohort. J Am Coll Cardiol. 1999;33(7):1948-1955. 
13. Sweitzer NK, Lopatin M, Yancy CW, Mills RM, Stevenson LW. Comparison of clinical features and outcomes of patients hospitalized with heart failure and normal ejection fraction $(>$ or $=55 \%)$ versus those with mildly reduced ( $40 \%$ to $55 \%$ ) and moderately to severely reduced ( $<40 \%$ ) fractions. Am J Cardiol. 2008;101(8):1151-1156.

14. Farr MJ, Lang CC, Lamanca JJ, et al. Cardiopulmonary exercise variables in diastolic versus systolic heart failure. Am J Cardiol. 2008; 102(2):203-206

15. Liao L, Jollis JG, Anstrom KJ, et al. Costs for heart failure with normal vs reduced ejection fraction. Arch Intern Med. 2006;166(1):112-118.

16. Yancy CW, Fonarow GC, Committee ASA. Quality of care and outcomes in acute decompensated heart failure: The ADHERE Registry. Curr Heart Fail Rep. 2004;1(3):121-128.

17. Adamson PB, Magalski A, Braunschweig F, et al. Ongoing right ventricular hemodynamics in heart failure: Clinical value of measurements derived from an implantable monitoring system. J Am Coll Cardiol. 2003; 41(4):565-571.

18. Tallaj JAP, Aaron M, Abraham W, Heywood JBR, Cho Y, Bennett T. Relationship between right ventricular pressures and heart failure events in patients with heart failure. J Card Fail. 2007;13(6):S178-S179.

19. Zile MR, Bennett TD, St John Sutton M, et al. Transition from chronic compensated to acute decompensated heart failure: Pathophysiological insights obtained from continuous monitoring of intracardiac pressures. Circulation. 2008;118(14):1433-1441.

20. Kjaergaard J, Akkan D, Iversen KK, et al. Prognostic importance of pulmonary hypertension in patients with heart failure. Am J Cardiol. 2007;99(8):1146-1150.

21. Kjaergaard J, Akkan D, Iversen KK, Kober L, Torp-Pedersen C, Hassager C. Right ventricular dysfunction as an independent predictor of short- and long-term mortality in patients with heart failure. Eur J Heart Fail. 2007;9(6-7):610-616.

22. Neuman Y, Kotliroff A, Bental T, Siegel RJ, David D, Lishner M. Pulmonary artery pressure and diastolic dysfunction in normal left ventricular systolic function. Int J Cardiol. 2008;127(2):174-178.

23. Dini FL, Nuti R, Barsotti L, Baldini U, Dell'Anna R, Micheli G. Doppler-derived mitral and pulmonary venous flow variables are predictors of pulmonary hypertension in dilated cardiomyopathy. Echocardiography. 2002;19(6):457-465.

24. Enriquez-Sarano M, Rossi A, Seward JB, Bailey KR, Tajik AJ. Determinants of pulmonary hypertension in left ventricular dysfunction. J Am Coll Cardiol. 1997;29(1):153-159.

25. Heywood JT, Fonarow GC, Costanzo MR, et al. High prevalence of renal dysfunction and its impact on outcome in 118,465 patients hospitalized with acute decompensated heart failure: A report from the ADHERE database. J Card Fail. 2007;13(6):422-430.

26. Ahmed A, Rich MW, Sanders PW, et al. Chronic kidney disease associated mortality in diastolic versus systolic heart failure: A propensity matched study. Am J Cardiol. 2007;99(3):393-398.

27. Maeder MHD, Kaye D. Does tricuspid regurgitation contribute to renal dysfunction in patients with heart failure. J Card Fail. 2008; 14(6S):S84.

28. Mullens W, Abrahams Z, Francis GS, et al. Importance of venous congestion for worsening of renal function in advanced decompensated heart failure. J Am Coll Cardiol. 2009;53(7):589-596.

29. Lee DAP, Stukel T, Alter D, Chong A, Parker J, Tu J. "Dose-dependent" impact of recurrent cardiac events on mortality in patients with heart failure. Am J Med. 2009;122:162.e161-e162.

30. Setoguchi S, Stevenson LW, Schneeweiss S. Repeated hospitalizations predict mortality in the community population with heart failure. Am Heart J. 2007;154(2):260-266.

31. Ramasubbu K, Deswal A, Herdejurgen C, Aguilar D, Frost AE. A prospective echocardiographic evaluation of pulmonary hypertension in chronic hemodialysis patients in the United States: Prevalence and clinical significance. Int J Gen Med. 2010;3:279-286.

32. Damman K, Voors AA, Hillege HL, et al. Congestion in chronic systolic heart failure is related to renal dysfunction and increased mortality. Eur J Heart Fail. 2010;12(9):974-982.
33. Dongaonkar RM, Stewart RH, Geissler HJ, Laine GA. Myocardial microvascular permeability, interstitial oedema, and compromised cardiac function. Cardiovasc Res. 2010;87(2):331-339.

34. Patton KK, Sotoodehnia N, Defilippi C, Siscovick DS, Gottdiener JS, Kronmal RA. N-terminal pro-B-type natriuretic peptide is associated with sudden cardiac death risk: The Cardiovascular Health Study. Heart Rhythm. October 30, 2010. [Epub ahead of print].

35. Uriel N, Torre-Amione G, Milo O, et al. Echocardiographic ejection fraction in patients with acute heart failure: Correlations with hemodynamic, clinical, and neurohormonal measures and short-term outcome. Eur J Heart Fail. 2005;7(5):815-819.

36. Zile MR, Baicu CF, Bonnema DD. Diastolic heart failure: Definitions and terminology. Prog Cardiovasc Dis. 2005;47(5):307-313.

37. Ommen SR, Nishimura RA, Appleton CP, et al. Clinical utility of Doppler echocardiography and tissue Doppler imaging in the estimation of left ventricular filling pressures: A comparative simultaneous Doppler-catheterization study. Circulation. 2000;102(15): 1788-1794.

38. Lester SJ, Tajik AJ, Nishimura RA, Oh JK, Khandheria BK, Seward JB. Unlocking the mysteries of diastolic function: Deciphering the Rosetta Stone 10 years later. J Am Coll Cardiol. 2008;51(7):679-689.

39. Liang HY, Cauduro SA, Pellikka PA, et al. Comparison of usefulness of echocardiographic Doppler variables to left ventricular end-diastolic pressure in predicting future heart failure events. Am J Cardiol. 2006; 97(6):866-871.

40. Maurer MS, Packer M, Burkhoff D. Diastolic heart failure. $N$ Engl J Med. 2004;351(11):1143-1145.

41. Maurer MS, Spevack D, Burkhoff D, Kronzon I. Diastolic dysfunction: Can it be diagnosed by Doppler echocardiography? J Am Coll Cardiol. 2004;44(8):1543-1549.

42. Nishimura RA, Abel MD, Hatle LK, et al. Significance of Doppler indices of diastolic filling of the left ventricle: Comparison with invasive hemodynamics in a canine model. Am Heart J. 1989;118(6): 1248-1258.

43. Nishimura RA, Appleton CP, Redfield MM, Ilstrup DM, Holmes DR Jr, Tajik AJ. Noninvasive doppler echocardiographic evaluation of left ventricular filling pressures in patients with cardiomyopathies: A simultaneous Doppler echocardiographic and cardiac catheterization study. J Am Coll Cardiol. 1996;28(5):1226-1233.

44. Nishimura RA, Tajik AJ. Evaluation of diastolic filling of left ventricle in health and disease: Doppler echocardiography is the clinician's Rosetta Stone. J Am Coll Cardiol. 1997;30(1):8-18.

45. Lam CS, Roger VL, Rodeheffer RJ, et al. Cardiac structure and ventricular-vascular function in persons with heart failure and preserved ejection fraction from Olmsted County, Minnesota. Circulation. 2007; 115(15):1982-1990.

46. Masutani S, Little WC, Hasegawa H, Cheng HJ, Cheng CP. Restrictive left ventricular filling pattern does not result from increased left atrial pressure alone. Circulation. 2008;117(12):1550-1554.

47. Mullens W, Borowski AG, Curtin RJ, Thomas JD, Tang WH. Tissue Doppler imaging in the estimation of intracardiac filling pressure in decompensated patients with advanced systolic heart failure. Circulation. 2009;119(1):62-70.

48. Troughton RW, Prior DL, Frampton CM, et al. Usefulness of tissue doppler and color M-mode indexes of left ventricular diastolic function in predicting outcomes in systolic left ventricular heart failure (from the ADEPT study). Am J Cardiol. 2005;96(2):257-262.

49. Olson JM, Samad BA, Alam M. Prognostic value of pulse-wave tissue Doppler parameters in patients with systolic heart failure. Am J Cardiol. 2008;102(6):722-725

50. Acil T, Wichter T, Stypmann J, et al. Prognostic value of tissue Doppler imaging in patients with chronic congestive heart failure. Int J Cardiol. 2005;103(2):175-181.

51. Bierig SM, Ryan A, Ziaee A, et al. Serial changes in systolic and diastolic echocardiographic indices as predictors of outcome in patients with decreased left ventricular ejection fraction. Eur J Echocardiogr. 2007;8(5):369-374. 
52. Bruch C, Gotzmann M, Sindermann J, et al. Prognostic value of a restrictive mitral filling pattern in patients with systolic heart failure and an implantable cardioverter-defibrillator. Am J Cardiol. 2006;97(5): 676-680.

53. Meta-analysis Research Group in Echocardiography (MeRGE) Heart Failure Collaborators. Independence of restrictive filling pattern and LV ejection fraction with mortality in heart failure: An individual patient meta-analysis. Eur J Heart Fail. 2008;10(8):786-792.

54. Grewal J, McCully RB, Kane GC, Lam C, Pellikka PA. Left ventricular function and exercise capacity. JAMA. 2009;301(3):286-294.

55. Brucks S, Little WC, Chao T, et al. Contribution of left ventricular diastolic dysfunction to heart failure regardless of ejection fraction. Am J Cardiol. 2005;95(5):603-606.

56. Samad BA, Olson JM, Alam M. Characteristics of left ventricular diastolic function in patients with systolic heart failure: A Doppler tissue imaging study. J Am Soc Echocardiogr. 2005;18(9):896-900.

57. Redfield MM, Jacobsen SJ, Burnett JC Jr, Mahoney DW, Bailey KR, Rodeheffer RJ. Burden of systolic and diastolic ventricular dysfunction in the community: Appreciating the scope of the heart failure epidemic. JAMA. 2003;289(2):194-202.

58. Ommen SR, Nishimura RA. A clinical approach to the assessment of left ventricular diastolic function by Doppler echocardiography: Update 2003. Heart. 2003;89 Suppl 3:iii18-23.

59. Caruana L, Petrie MC, Davie AP, McMurray JJ. Do patients with suspected heart failure and preserved left ventricular systolic function suffer from "diastolic heart failure" or from misdiagnosis? A prospective descriptive study. BMJ. 2000;321(7255):215-218.

60. Grigorian-Shamagian L, Otero Ravina F, Abu Assi E, et al. Why and when do patients with heart failure and normal left ventricular ejection fraction die? Analysis of $>600$ deaths in a community long-term study. Am Heart J. 2008;156(6):1184-1190.

61. Al-Khatib SM, Shaw LK, O’Connor C, Kong M, Califf RM. Incidence and predictors of sudden cardiac death in patients with diastolic heart failure. J Cardiovasc Electrophysiol. 2007;18(12):1231-1235.

62. Grigorian Shamagian L, Gonzalez-Juanatey JR, Roman AV, Acuna JM, Lamela AV. The death rate among hospitalized heart failure patients with normal and depressed left ventricular ejection fraction in the year following discharge: Evolution over a 10-year period. Eur Heart J. 2005;26(21):2251-2258.

63. Yancy CW, Lopatin M, Stevenson LW, de Marco T, Fonarow GC. Clinical presentation, management, and in-hospital outcomes of patients admitted with acute decompensated heart failure with preserved systolic function: A report from the Acute Decompensated Heart Failure National Registry (ADHERE) Database. J Am Coll Cardiol. 2006;47(1):76-84.
64. Richardson A, Bayliss J, Scriven AJ, Parameshwar J, Poole-Wilson PA, Sutton GC. Double-blind comparison of captopril alone against frusemide plus amiloride in mild heart failure. Lancet. 1987;2(8561): 709-711.

65. Cowley AJ, Stainer K, Wynne RD, Rowley JM, Hampton JR. Symptomatic assessment of patients with heart failure: Double-blind comparison of increasing doses of diuretics and captopril in moderate heart failure. Lancet. 1986;2(8510):770-772.

66. van Kraaij DJ, Jansen RW, Bruijns E, Gribnau FW, Hoefnagels WH. Diuretic usage and withdrawal patterns in a Dutch geriatric patient population. J Am Geriatr Soc. 1997;45(8):918-922.

67. Mathur PN, Pugsley SO, Powles AC, McEwan MP, Campbell EJ. Effect of diuretics on cardiopulmonary performance in severe chronic airflow obstruction. A controlled clinical trial. Arch Intern Med. 1984; 144(11):2154-2157.

68. Andrews R, Charlesworth A, Evans A, Cowley AJ. A double-blind, cross-over comparison of the effects of a loop diuretic and a dopamine receptor agonist as first line therapy in patients with mild congestive heart failure. Eur Heart J. 1997;18(5):852-857.

69. Grinstead WC, Francis MJ, Marks GF, Tawa CB, Zoghbi WA, Young JB. Discontinuation of chronic diuretic therapy in stable congestive heart failure secondary to coronary artery disease or to idiopathic dilated cardiomyopathy. Am J Cardiol. 1994;73(12):881-886.

70. Guglin M. Reappraisal of the role of diuretics in heart failure. Cardiol Rev. 2009;17(2):56-59.

71. Domanski M, Norman J, Pitt B, Haigney M, Hanlon S, Peyster E. Diuretic use, progressive heart failure, and death in patients in the Studies Of Left Ventricular Dysfunction (SOLVD). J Am Coll Cardiol. 2003;42(4):705-708.

72. Domanski M, Tian X, Haigney M, Pitt B. Diuretic use, progressive heart failure, and death in patients in the DIG study. J Card Fail. 2006; 12(5):327-332.

73. Eshaghian S, Horwich TB, Fonarow GC. Relation of loop diuretic dose to mortality in advanced heart failure. Am J Cardiol. 2006;97(12): 1759-1764.

74. Testani JM, Chen J, McCauley BD, Kimmel SE, Shannon RP. Potential effects of aggressive decongestion during the treatment of decompensated heart failure on renal function and survival. Circulation. 2010;122(3):265-272.
International Journal of General Medicine

\section{Publish your work in this journal}

The International Journal of General Medicine is an international, peer-reviewed open-access journal that focuses on general and internal medicine, pathogenesis, epidemiology, diagnosis, monitoring and treatment protocols. The journal is characterized by the rapid reporting of reviews, original research and clinical studies across all disease areas.

\section{Dovepress}

A key focus is the elucidation of disease processes and management protocols resulting in improved outcomes for the patient.The manuscript management system is completely online and includes a very quick and fair peer-review system. Visit http://www.dovepress.com testimonials.php to read real quotes from published authors. 